\title{
EDITORIAL
}

\section{Ethiopian Journal of Health Sciences Stepping Forward}

Established under the former Jimma Institute of Health Sciences, now called Jimma University, the Ethiopian Journal of Health Sciences (EJHS) published its first issue in July 1990 with the name "Bulletin of Jimma Institute of Health Sciences". Since then, EJHS has been publishing peer-reviewed articles on a variety of topics pertaining to public health and medicine. The journal has always strived to:

1. provide current scientific and technological information on health and related fields for informed planning and decision making;

2. contribute to the scientific knowledge and practices in medicine, public health and related fields by providing a formal means for researchers to share their scientific research works, observations and experiences.

In the last twenty-four years, EJHS made several strides to reach scientists, academicians, policy makers and other readers or users locally and globally. To this end, the journal underwent several quantitative and qualitative transformations.

From its inception to 1995, the Ethiopian Journal of Health Sciences was a biannual publication named "Bulletin of Jimma Institute of Health Sciences". In those years, the journal changed in form, cover colour, contents and sources of manuscripts. Its form changed from A-5 to A-3 and its cover colour from yellow to white and then to blue. Its contents changed significantly in quantity and quality during those six years. However, almost all the manuscript contributors during this period were from the then Jimma Institute of Health Sciences.

The next stage in the history of EJHS covers the years of 1996-2006. During this period, the journal was sluggish in its development. The notable change in this period was the alteration of its name, i.e. from "Bulletin of Jimma Institute of Health Sciences" to "Ethiopian Journal of Health Sciences (EJHS)", which happened in line with the establishment of a full-fledged Jimma University. However, the biannual appearance, the format A-5 size and the blue colour remained unchanged. In addition, the type of articles, the quantity and the quality of the articles published in each issue did not show noticeable changes. Nevertheless, unlike before, few authors from other parts of Ethiopia contributed manuscripts, while there were not any international contributors yet.

The Ethiopian Journal of Health Sciences achieved a remarkable development from 2007 through 2013. The first two fundamental changes accomplished in this period were the change in format from A-5 to A-3 and the growth in frequency from biannual to triannual publication. Following these changes, the quantity and quality of articles published in successive issues improved substantially. In 2008, EJHS joined African Journals Partnership Project (AJPP), which is funded by the US National Institute of Health/National Library of Medicine (NLM) from which it got capacity building supports. With the help of this project, the Editor-in-Chief of EJHS became member of the Council of Science Editors. The project [AJPP] also helped EJHS partner with the prestigious Annals of Internal Medicine published by American College of Physicians from which EJHS it gained a great deal. In 2009, the Ethiopian Journal of Health Sciences launched its own website where all publications are uploaded for open access. In 2010, the journal began using ScholarOne-Manuscript Central software for manuscript management, and this heralded the end of submission of manuscripts in print copies. That is, since then, the manuscript management process has been undertaken using this software system. The same year, EJHS joined Committee for Publication Ethics (COPE). The following year, it was indexed on PubMed Central, African Journal Online (AJOL) and EBSCO. Again, in the end of the year 2012, it was indexed on MEDLINE. Although EJHS did not win the competition to become member of International Committee of Medical Journal Editors (ICMJE) in 2011, it succeeded in 2013 as a result of which the Editor-in-Chief joined this international group. This international involvement in effect helped increase the visibility of the journal considerably. This has been evidenced by the consistent growth in the number of readers and the massive submission of manuscripts from all parts of the world. The number of manuscript submission 
has increased from about 35 in the past to nearly 200 a year currently; and publication from an average twenty to forty yearly. This phenomenon called for an increase in the frequency of publication.

The 24 years old Ethiopian Journal of Health Sciences has thus has been upgraded to a quarterly publication with Vol. 24, No.1 (January 2014 issue) being the first in this development. As EJHS continues to thrive in the science world, I believe that authors, editors, reviewers and partners will continue extending concerted efforts for a better effect.

The current issue (Vol. 24, No 1), the first issue in the leap of EJHS to a quarterly publication, contains ten original articles on diverse issues and four case reports focusing on various cases of rarity. I invite readers to read through these articles and appreciate or utilize the contents. I also encourage readers to forward comments and suggestions.

Abraham Haileamlak (MD)

Editor-in-Chief 